\title{
Indoor Outdoor Playground Learning Environment Setting Design to Enhance Children's Multiple Intelligence Potential
}

\author{
Rita Mariyana, Ocih Setiasih \\ Indonesia University of Education \\ Corresponding e-mail: ritamariyana@upi.edu
}

\begin{abstract}
The purpose of this study is to develop a design model that integrates indoor and outdoor playground learning environment setting in order to optimize early childhood multiple intelligence. There were three stages of research and development applied in this research. The first stage was developing multiple intelligence instrument which was needed to support design model of integrated indoor and outdoor playground learning environment setting. The second stage was designing a model of integrated indoor and outdoor playground learning environment setting to optimize children's multiple intelligence based on development stage. The third stage was implementation of design model of integrated indoor and outdoor playground learning environment setting to develop children's multiple intelligence in early childhood educational institution. The findings of this study discover that the planning of indoor and outdoor playgrounds should be well-prepared, in order to support the development of children's multiple intelligence. Hence, it is recommended that every early childhood teacher has to show environmental influence to the children, which is in line with daily, weekly and annual activity plans.
\end{abstract}

Keywords: Learning Environment, Indoor and Outdoor Playground, Multiple Intelligence

\section{INTRODUCTION}

Nowadays, the needs of quality playground has been considered as an important aspect to support children development. This consideration arises as children learn best through playing. They can play both in indoor and outdoor areas.

Another aspect to consider in children learning is the development of their intelligence. A theory proposed by Gardner named multiple intelligence assumes that every child has a potential to be genius. Children have admiration, curiosity, spontaneity, vitality, and flexibility. They are also able to accelerate towards every given stimulus.

Early childhood learning environment should provide playing ground that make them free to move, to be creative, and to explore, including applying certain manipulation to make children exposed to new behavior from the activity. A study conducted by Omotuyole (2014) discovers that the environment of the pre-school children should provide nourishment for the children's language and overall development and that the content and their learning styles should be quite different from those of the adults.

Therefore, in order to fully develop children intelligence, there is an urgency to provide indoor and outdoor playgrounds. The Indoor playground will be used as children' learning place to exercise their various potential. There are several things to consider in establishing indoor playground, namely: room, floor condition, class wall, palate, and another thing that is needed to maintain fun and comfortable learning environment.

Outdoor playground is an integrated part of a children development and learning program. It is advantageous and effective in helping the development of children's multiple intelligence. Therefore, outdoor playground learning environment should properly and seriously organized.

It is important to provide conducive learning environment for children in order to stimulus and develop their multiple intelligence potential, which is possessed variously, so by developing design model of integrated indoor learning environment and 
outdoor playground setting could improve the children's multiple intelligence potential.

On the other hand, it is a collective obligation of teacher and parents to maintain children's intelligence level. Children's natural state of genius should be maintained optimally through parents and teacher guidance, and provision of conducive learning environment to optimize their multiple intelligence.

Based on the aforementioned issues, this research seeks to develop the concept and setting of indoor learning environment and outdoor playground to advance children's multiple intelligence potential. The final product of this research is a design of indoor learning environment and outdoor playground setting to optimize young learner's multiple intelligence potential.

\section{LITERATURE REVIEW}

Every child is sensitive in receiving any stimulus as long as their psychological and physical functions are ready to the stimulus given by the environment. A learning environment can develop various developmental stage of children optimally if it is designed carefully and properly. Thus, specific planning and environment selection should be considered seriously. On the other hand, learning environment is one of the key factors in developing children's capability, behavior, and multiple intelligence. So that, its implication should prioritize children's learning environment.

Derived from the words "environment" and "learning", learning environment could be interpreted as place or condition that could influence human behavior changing process. From the explanation, it can be inferred that changing that resulted from the environment could impact relatively permanent. In meaning that the stronger environmental influence leads to greater predicted change on the subject. It proves how big the environmental influence towards children's learning behavior. That is why it will be very good for teachers to show environmental influence in the individual development, especially children (Mariyana et al., 2010).

\subsection{Children's Learning Environment}

In pre-school period, children are very sensitive in accepting every stimulus which, since both of their physical and psychological functions are ready to respond to any stimulus given by the environment. Therefore, environment as an element that supplies and provides certain stimulus is needed to get serious attention. Specific planning and selection are required to provide suitable environment needed by children, in order to lead the children to the intended behavior.

Learning environment is a place where students can express themselves to do activities and create something, including doing various manipulation in many ways to get new behavior from the activity. In another word, learning environment can be interpreted as "laboratory" or a place for children to explore, experiment, and express themselves to get new concept or information as a form of learning result. Therefore, when the subject is children, then the environment is learning environment intended for children (Mariyana, 2010).

Based on the aforementioned explanation, it could be further inferred that changing that is generated by the environment could be stiff and relatively permanent. Thus, early childhood teachers are expected to show their environmental influence children development (Mariyana et al., 2010).

\subsection{Indoor Environment for Children}

The indoor environment is very important for children. It should be familiar, comforting, and it eases transitions from home care to early year settings. This may involve applying the physical environment with soft furnishing, small room and quiet spaces. The best settings eases transition by catering for all children, (Beckley, 2012).

In order to get ideal classroom, we have to pay attention to its setting. Indoor playing room for children is commonly a large square room, but it has some dividers that separates one area with another. In every corner of the room, usually there is a storage to put certain stuffs that could be used in the activities.

Younger children (around 3-4 years) classroom is usually being set in simpler shape. All learning activities are happened in a certain room and children can freely sit in the floor. The principle is the activities are done in areas that is designed based on the needs (Mariyana et al., 2010).

\subsection{Outdoor Environment for Children}

An enabling outdoor environment is also one that encourages curiosity, inquiry and exploration, having a number of sensual experiences for children to encourage them to use all their senses, where safe (Johnston 2005, in Beckley 2012). 
Outdoor activity is one of the integrated parts of early childhood education. According to Froebel (in Mariyana et al., 2010) children play mate is "natural". Children are expected to be exposed to certain activities like keeping their garden, building a damn, petting animal, and doing games. Besides children like fresh air and broad area, outdoor activity provides more facilities that can be used to help their development.

\subsection{Children's Multiple Intelligence Optimization}

Through outdoor activity all parts of children development can be improved. It is happened because outdoor activity involves multiple aspects in children development. Outdoor activity effectively integrates children's sensory with various potential. It includes physical, social capability, cultural knowledge, emotional, and intellectual development.

Multiple intelligence is a term in study of intelligence, which was proposed by American education expert named Howard Gardner. There are various interpretation towards multiple intelligence, some define it as double intelligence, compound intelligence, and plural intelligence. In this research, the term used is multiple intelligence.

In general, multiple intelligence proposed by Howard Gardner (2004) consists of:

1. Linguistic intelligence (Verbal)

2. Logic-Mathematic intelligence (LogicMathematic)

3. Spatial intelligence (Space)

4. Kinesthetic intelligence (Physical and Movement)

5. Musical intelligence (Music)

6. Interpersonal intelligence

7. Intrapersonal intelligence (Personal)

8. Naturalist intelligence (Nature)

\subsection{Identifying Children's Multiple Intelligence}

Gardner's theory of multiple intelligences resonates so strongly for many educators because it offers a model for acting on what we believe: all children have strengths. Many of us were taught to focus on the curriculum as we planned and taught, to concentrate on helping students respond to the curriculum; MI, however, is a student-centered model in which the curriculum is often modified to fit the students. Rather than relying upon a linguistic filter and requiring students to write to show their grasp of skills and information, teachers using MI can allow students to use their strengths to demonstrate what they have learned. Students might use their spatial intelligence in drawing, their musical intelligence in composing a song or identifying a melody, or their bodily-kinesthetic intelligence in acting out an interaction or creating a diorama. (Hoerr, Thomas, 2000).

If we could free ourselves from the myth, which states that there are intelligence and less intelligence people, we are entering a new perspective. The right thing to say is that there are people who good in particular thing and less capable in another area. Developing a profile of a person multiple intelligence is not a simple thing. Once more, there is no (intelligence) test that could determine potential and quality of a person's multiple intelligence. Standardized test (currently), like the one developed by Howard Gardner (2004), only measure small portion of whole spectrum of ability. The realistic assessment to assess someone's multiple intelligence is through series of tasks, activities and experiences that associate one intelligence with another. However, this will require long time to assess.

Even though it is true that every child has all intelligences and could develop it into high level, child seems to show what Garner (2004) said as tendency towards certain intelligences in the very young age. In the period of entering school, they probably already determine their own learning ways that are more suitable with some intelligences compare to the others.

Children who are dominant in thinking, like activity that require linguistic skills in reading, writing, telling story, and word games, etc. They also like books, cassette, paper, diary, dialogue, discussion, debate, stories, etc. Logic-mathematic children prefer experimenting, questioning, solving logical puzzle, counting, etc. Things that could be investigated and think about, science materials that could be modify, visiting planetarium or science museum. They also like geometry, design, drawing, visualizing, etc.; and also art, Lego, video, film, slide, imagination games, maze, puzzle, illustration book, visiting dance museum. Children with physical intelligence enhances through somatic sensation of dance, running, jumping, building, touching, representation, drama, movement, things that could be built, sports, and physical games, direct learning, etc. Children with musical intelligence enhance through rhythm and melody, singing, whistle, percussion, listening, singing together, come to concert, playing music in school and home, playing instruments, etc. Interpersonal children 
enhances through discussing idea with others, leading, organizing, making relation, manipulating, judging, partying, making friends, play group, social gathering, community event, student clubs. Intrapersonal children enhances through deep within themselves forming purposes, meditating, dreaming, stops, planning. They like secret places, time for alone, personal project, choices. Lastly, children with natural intelligence enhance through making analogy of natural condition, being in nature, exploring, connecting, touching soils, water, animals, and wind.

\section{METHODOLOGY}

Approach used in this research is Research and Development approach, since the purpose of this research is to develop a design and model of integrated indoor learning environment and outdoor playground which could maximize children emotional intelligence potential.

Research and Development was done in ten stages including: (1) research and information collecting, (2) planning, (3) develop preliminary from of product, (4) preliminary field testing, (5) main product revision, (6) main filed testing, (7) operational product revision, (8) operational field testing, (9) final product revision and, (10) dissemination and implementation.

Research and Development is a mix method research that combines qualitative and quantitative approaches. Hence, the design model for qualitative approach was implemented through steps of: (1) formulating indoor and outdoor environment development design that can increase the potential of children's multiple intelligence; (2) developing initial design indoor and outdoor environment that could enhance multiple intelligence potential, which includes model, setting, execution, and evaluation towards indoor and outdoor environment design that had developed.

\section{FINDING AND DISCUSSION}

The setting of indoor and outdoor playground to enhance children multiple intelligence potential could be seen in the following picture:

\section{School Layout}
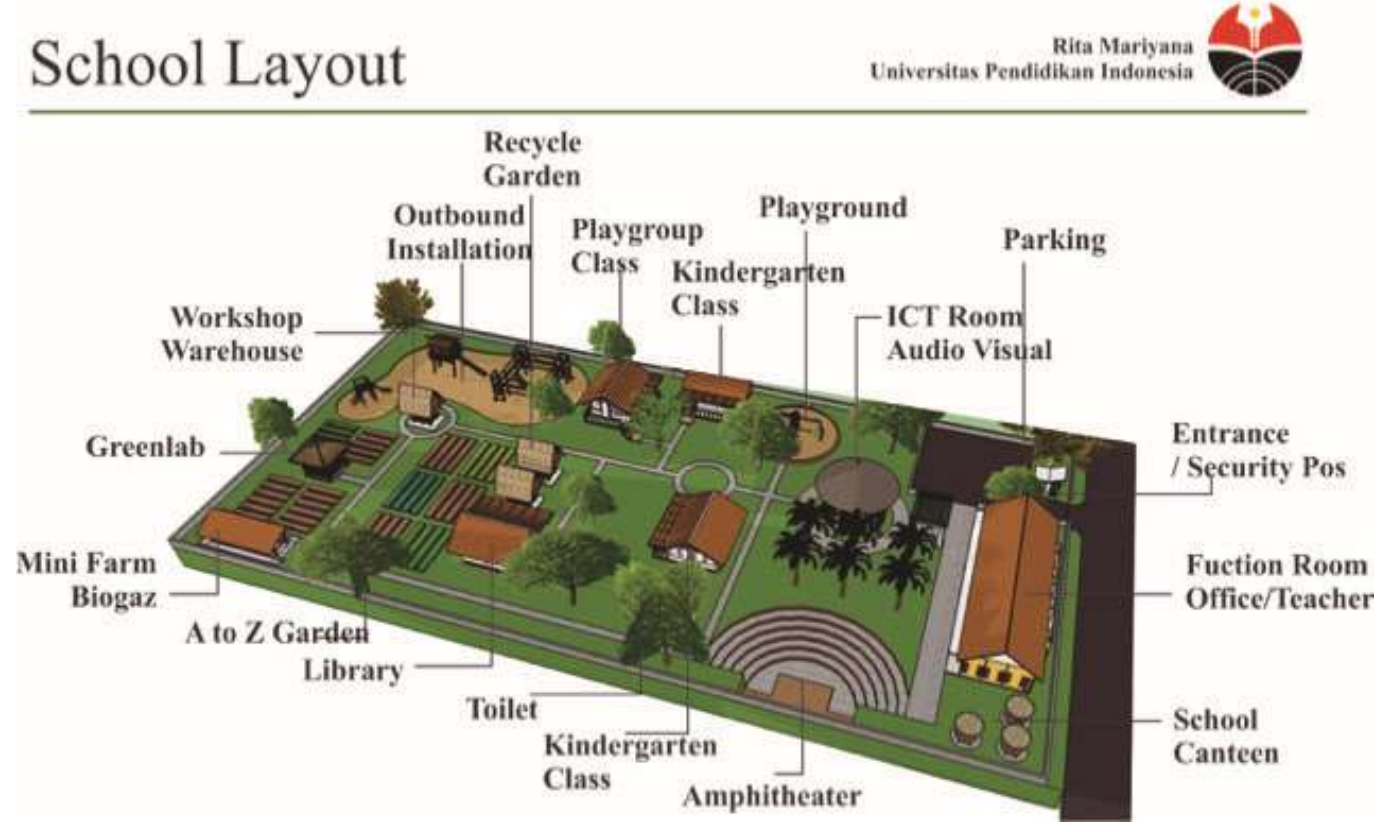

Figure 1. Integrated Design of Indoor and Outdoor Playground

As seen in Figure 1, a school layout that provides integrated design of indoor and outdoor playground should at least have outbound installation, recycle garden, playgroup class, kindergarten class, playground, ICT room audio visual, parking lot, function room, school canteen, amphitheater, toilet, library, A to Z garden, mini farm, green lab and workshop areas. This kind of design is designed to fully develop all of the multiple intelligences aspects. 
Using MI-informed approaches usually involves an iterative process between curriculum/instruction and assessment. MI theory helps teachers frame activities so that many entry points into the subject matter are available to students. Teachers use the knowledge they have accumulated about students' intelligences and preferences to inform subsequent instruction. Teachers who offer different pedagogical approaches and allow exploration of differing perspectives create the possibility of reaching more students more effectively. (Baum, et al., 2005)

\section{CONCLUSIONS}

There are many ways in making conducive learning atmosphere where multiple intelligence becomes the basic concept in early childhood learning process. As long as previous consideration is applied, the children are being served with a condition where they can fully grow and develop. They are not forced to be something that is not suitable with their unique ability and preference. In another word, educator has a role as midwife who is assisting the process of giving birth. She patiently, carefully, and wisely helps the process. It is going to be a pride when the process has resulted optimal development and growth.

The specific conclusions of the research are:

1. The formulation, planning and definition of indoor learning environment and outdoor playground design setting, which can enhance the potential of children's multiple intelligence, is the one that is consciously designed to support children's multiple intelligence enhancement.

2. Design setting guidance of indoor environment and outdoor playground that could enhance children's multiple intelligence potential is a plan that is purposely formulated to guide learning process to support children's multiple intelligence in form of Lesson Plan Activity namely: Daily Activity Plan (DAP), Weekly Activity Plan (WAP), and Annual Activity Plan (AAP) which are integrated in children's learning process.

\section{REFERENCES}

Omotuyole, Afoma R. Okudo Christy. (2014). Enhanced Learning Environment and Its Implications on the Pre-School Children's Language Performance. European Scientific
Journal March 2014 edition vol.10, No.7 ISSN: 1857 - 7881 (Print) e - ISSN 1857- 7431

Baum, Julie, Viens, and a Barbara Slatin. (2005). Multiple Intelligences in the Elementary Classroom a Teacher's Toolkit. Teachers College: Columbia University New York and London

Brendon P Hyndman, Amanda C Benson, Shahid Ullah and Amanda Telford. (2014). Evaluating the effects of the Lunchtime Enjoyment Activity and Play (LEAP) school playground intervention on children's quality oflife, enjoyment and participation in physical activity. Hyndman et al. BMC Public Health 2014, 14:164

Beckley, Pat. (2012). Learning in Early Childhood. Sage Publication Ltd

Gardner, Howard. (2004). Frames of Mind The Theory of Multiple Intelligences. Basic Book: New York

Hoerr, Thomas. (2000). Becoming Multiple Intellegences Schools. Virgnia : ASCD.

Mariyana, Rita, dkk. (2010). Pengelolaan Lingkungan Belajar. Jakarta: Prenada Media Group 